\title{
I. Kosovar Youth Doing Tikkun: Insights from a Research-Based Action Project for Social Justice and Reconciliation
}

ERWIN DIMITRI SELIMOS, EREBLIR KADRIU, AND JANET BALYEAT

\section{Abstract}

Drawing on peer-to-peer interviews conducted by/with highly-engaged Kosovar youth, this chapter considers how they make sense of their social activism within the context of a post-war Kosovar society. In particular, we identify how they learn about issues of social concern and take an active role in addressing these concerns. Analysis demonstrates that traditional institutions of socialization, personal experiences, and a strong sense of attachment to local place are important factors motivating their social change efforts. Furthermore, their social change efforts most often take place in non-governmental and youth-focused organizations, which enable but also shape the topics and nature of their social change agenda. Although highly-engaged Kosovar youth view their social engagement as important to building a better society, they also understood it as a means of gaining skills and experiences advantageous in a society which is attempting to integrate into the European Union. Finally, social change activities have important and positive benefits on young people's sense of self and often result in important practical changes to their local communities.

Keywords: Kosovo; Kosovar youth; youth activism; peer-to-peer research

It has now been nearly 20 years since the end of the Serbian-Kosovo War. An entire generation of children born in or after 1999 has no living memory of life before the conflict. These young people have grown up in a society 
marked by intense social transformations including the introduction of capitalist consumer economies, access to global media, persistent interethnic animosities, and often overwhelming economic challenges including economic underdevelopment, joblessness, and poverty. Since the end of the Serbia-Kosovo war, state-builders and policymakers have viewed cultivating active citizenship among young people as essential to building a democratic state (Feltes, 2013). These policy initiatives aim to build young people's capacity to be active citizens and key actors in addressing the social divides characterizing the Kosovar society.

Within the context of these societal challenges and youth-targeted policy initiatives, this chapter considers how young people are attempting to make a difference. We draw on peer-to-peer interviews conducted by/with highly-engaged Kosovar youth to identify how they learn about issues of social concern and take an active role in addressing these concerns. We situate their experiences within the larger Kosovar context to consider how they make sense of and practice their social change efforts. We believe that a focus on young people's perspectives, situated within the complex socialcultural context of post-war Kosovo, provides a valuable angle to assess the implementation of post-war reconstruction policies that place priority on encouraging and cultivating active youth citizenship in Kosovo.

The chapter begins by providing an overview of the Kosovar youth situation within the context of post-war challenges and concerns. It then moves to a description of the study, the research process, and its main findings. The final section of the chapter identifies the significance of our project and points to important avenues for further exploration.

\section{Background and Context}

Kosovo is a partially-recognized independent state located in Southeastern Europe, northeast of Albania. Kosovo was an autonomous province of Serbia throughout the history of the Federal Republic of Yugoslavia. During the dissolution of Yugoslavia, a major conflict arose in the late-1990s between the Albanians of Kosovo and the Serbian military and militia. The basis of the war was Serbia's increasingly nationalistic and aggressive stance towards Albanians under the leadership of Slobodan Milosevic, who sought to claim 
the territory of Kosovo and Serbian-ize its population, territory, and institutions (Malcolm, 1998). After nearly a decade of non-violent resistance by Kosovar Albanians, open fighting broke out in the late 1990s between Serbian military and paramilitary forces and the Kosovo Liberation Army. The war saw overwhelming destruction, including the mass killing of Albanian civilians by the Serbian militia forces. The conflict ended in 1999 because of the North Atlantic Treaty Organization (NATO) intervention, after which Kosovo was placed under the administrative rule of the United Nations (Clark, 2000).

From 1999 to 2008, the United Nation Mission in Kosovo (UNMIK) acted as the main institution to deal with post-war challenges, directing various state-building efforts, which included establishing the main institutions of state governance (Feltes, 2013). In 2008, when Kosovo declared independence from Serbia, the United Nations steadily transitioned out of the country, handing over some supervisory authority to the European Union (EU). With a mandate to 2020, the European Union Rule of Law Mission in Kosovo (EULEX) monitors Kosovo's legal system, acting as a corruption watchdog and providing assistance to specific institutions of Kosovo's legal system (EULEX, n.d.). A central goal of the post-war reconstruction efforts has been the eventual integration of Kosovo into the European Union. Its succession into the European Union requires that it harmonizes policies, legislation, and procedural operations of its government institutions with EU standards and best practices. 


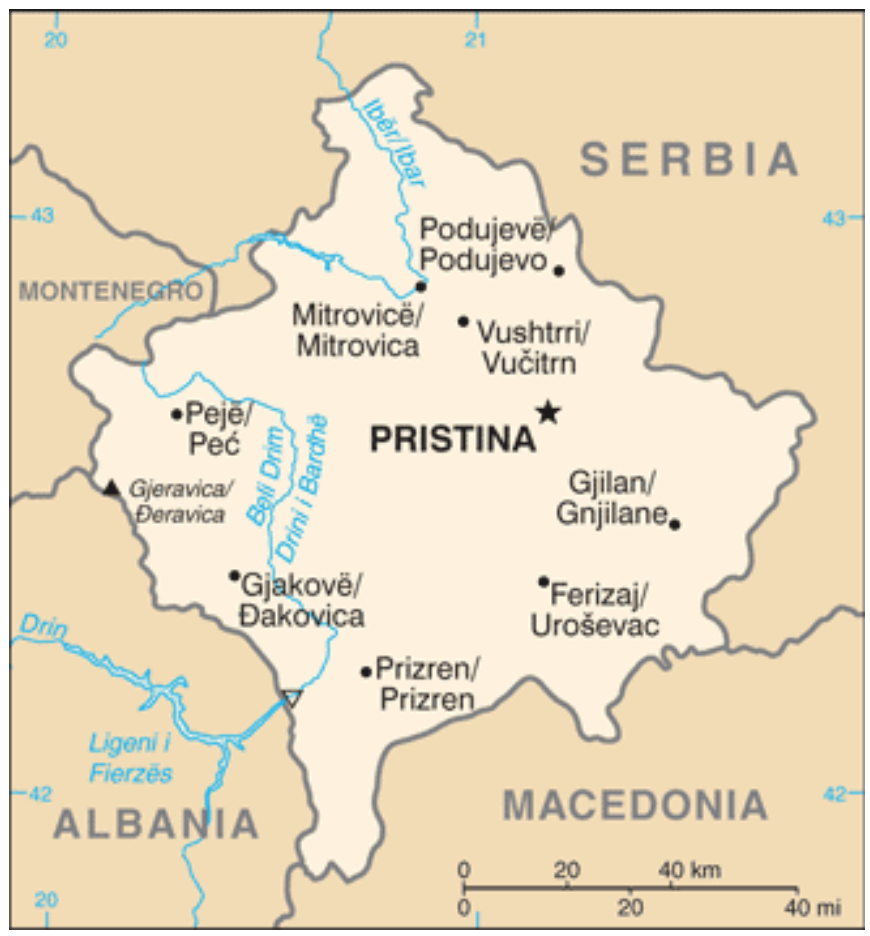

Figure 1. Map of Kosovo

Source: https://legacy.lib.utexas.edu/maps/cia16/kosovo sm 2016.gif

Currently, Kosovo's legitimacy is contested both internationally and locally. The country has yet to be recognized by all UN or EU member states, and in different parts of the country, primarily the northern area of Mitrovica, many Serbian residents do not recognize Kosovo as an independent country (Clark, 2000). Its succession into the European Union is opposed by European Union member states, including Greece and Spain, and furiously opposed by Serbia. As such, Kosovo remains a contested territory and an unsettled state (Krasniqi, 2013).

In addition to its territorial disputes, the country also faces significant social and economic challenges, including high levels of nepotism, economic underdevelopment, enduring structural unemployment and poverty, limited social protection systems (i.e., unemployment insurance, pension programs, healthcare, work condition regulations), as well as poor and uneven 
educational infrastructure (Feltes, 2013; Gjinovci, 2016; Gjocaj, 2016; Kosovo Agency of Statistics, 2017; UNDP Kosovo, 2017). A central challenge also remains building an inclusive society, as interethnic animosities and segregation, and concern over minority rights and the status of women in society persists (Clark, 2000).

\section{The Youth Situation in Kosovo}

Kosovo is among the youngest countries in Europe, with an average age of 30.2 years (Kosovo Agency of Statistics, 2017). In 2011, ninety-one percent of Kosovo's residents were ethnically Albanian, 3.4\% Serbian, and 5.6\% members of the Bosnian, Roma, Ashkali, and Egyptian (RAE), or Turkish communities (Kosovo Agency of Statistics, 2017). Most Kosovar youth, particularly young Albanians, identify as Muslim. Kosovo is also characterized by a substantial percentage of its population living in poverty. Drawing on official statistics collected by the Kosovo Agency of Statistics, Gjocaj (2016) reports that most Kosovar families are financially insecure, with about $30 \%$ of Kosovars living in relative poverty and $8.2 \%$ living in extreme poverty.

In 2012, the Friedrich Ebert Foundation and IDRA Research \& Consulting (Pasha, Xhangolli, Dundo, Gjokuta, Tahiri, \& Lena, 2012) released a report examining young Kosovars' attitudes and life orientations. Utilizing surveys and focus groups, the study points to important features of young Kosovars' current social and cultural situation. The study's focus on Albanian and Serbian Kosovar youth limits our capacity to generalize about the life situations of RAE, Bosnian, and Turkish youth, whose histories, conditions, and positions in society as ethnic minorities are unique.

In terms of general cultural orientations, Pasha et al. (2012) reveal that Kosovar youth remain conservative and traditional. This can be observed in their stance toward family and marriage. A strong familialism pervades: most young Kosovars place very strong trust in their families (compared to their mistrust of other social institutions, such as the government) and reside for a comparatively long time in their parents' household, usually until they themselves marry. Parents are actively involved in shaping children's life decisions, including the selection of marriage partners and educational and career pathways. Furthermore, the study illustrates that fathers play a 
central role when deciding children's career and educational decisions, while mothers remain "consultants of day-to-day, 'softer' issues" (Pasha et al., 2012, p. 13), suggesting enduring patriarchal elements of contemporary Kosovar family life.

The report also demonstrates entrenched attitudes of suspicion and animosity between different ethnic and religious groups. Albanian and Serbian Kosovar youth, who continue to live in segregated neighborhoods and cities, express significant mistrust of each other, and young Albanian and Serbian Kosovars' attitudes toward RAE, Turks, and Bosnians are characterized by mistrust and prejudice. Across these ethnic and religious divisions, however, the report documents that Kosovar youth are remarkably united over their high educational aspirations and their desire to access European and North American educational institutions. Kosovar youth, in general, express very strong support for Kosovo's integration into the European Union, which translates to them free movement and access to educational, cultural, and economic resources (Pasha et al., 2012).

Despite these educational and cultural aspirations, for many young Kosovars the promise of education and the desires for a European consumer-citizen life are frustrated by restricted travel. Unlike many of their European youth counterparts who enjoy unrestricted travel throughout Europe as members of the European Union, Kosovars are subject to strict visa regulations. Furthermore, the prospect of joblessness remains a persistent source of anxiety and despair, contributing to a strong desire among young people to live abroad (Cani, 2015; Tahiri, 2014). For example, in the first months of 2015, tens of thousands of Kosovars, mainly young people, crossed illegally into European Union countries via Serbia and Hungary to seek asylum in Germany. Most applicants were determined to be economic migrants-not refugees-and were denied asylum. The "exodus" of Kosovars was a symptom of the frustration and despair caused by joblessness and limited opportunities (Cani, 2015).

Ibrahim Berisha, a leading Kosovar sociologist, summarizes the current situation of many young people in Kosovo:

After a difficult period, Kosova's society is in a period of reconstruction, attempting to integrate itself into international financial, political, and cultural institutions. However, this integration, although it seems to offer hope, has not produced the results that citizens would like.... The failure of current policies to 
create more social equality has made young people cynical. Most young people want to leave Kosova, looking to the global job market as an opportunity to build a future. But success in the global market requires investment and change of the education system. (Berisha \& Kunushevci, 2017, para. 18-19)

In sum, our short sketch of the youth situation in Kosovo demonstrates that young Kosovars are confronted with the contradictions of being exposed to a globalizing youth culture, the promise of EU integration (with the types of opportunities this may provide), and the very real structural realities that shape their daily lives and restrict their possibilities. Although conservative yet increasingly global (and perhaps "European") in their orientations, desires, and consumption practices, their lives remain largely local: shaped by restricted travel, limited social resources and opportunities, poorly functioning state institutions, social inequality, interethnic animosities, and deeply entrenched nepotism.

\section{Kosovar Youth and the Promotion of Active Citizenship}

Since the end of the Serbia-Kosovo war, young people have figured centrally in the construction of a new Kosovar state. State-builders and policymakers have viewed cultivating active citizenship among young people as central to building a viable democratic state. The promotion of active citizenship among Kosovar youth has been encouraged and supported by the international community (especially the European Union), an array of government-sponsored policy initiatives, and the efforts of many youthfocused civil society organizations, all of which have come to characterize the social landscape of post-war Kosovo (Feltes, 2013). Two policy initiatives illustrate the centrality of cultivating active citizenship among youth as a tool in post-war reconstruction: the adoption of the Law on Empowerment and Participation of Youth (Republic of Kosovo, 2009) and the development of a four-year youth strategy titled Kosovo Strategy for Youth, 2013-2017 (Ministry of Culture, Youth and Sport, 2013).

On October 19, 2009, the Kosovar government adopted the Law on Empowerment and Participation of Youth (hereafter the Law), which makes youth participation mandatory for policy decisions in the fields of education, 
employment, public health, environment, spatial planning, and rural development (Republic of Kosovo, 2009). Among others, the Law considers the construction and operation of municipal youth centers as important nodes to achieving youth participation. Local youth centers are intended to provide a space for youth to socialize and access various activities and services, such as professional support for health and psychosocial issues, and any relevant trainings (Republic of Kosovo, 2009).

The Kosovo Youth Strategic Action Plan 2013-2017 (hereafter the Action Plan) aims to improve the general situation of Kosovo youth and align the country's youth sector policy priorities with European and international standards (Ministry of Culture, Youth and Sport, 2013). Its vision is to encourage

young men and women of Kosovo to become active, healthy, educated citizens, who enjoy a good and qualitative life and prepare to face all challenges of life as responsible members of local, regional, European and world community. (Ministry of Culture, Youth and Sport, 2013, p. 18)

A specific objective targets youth participation in decision-making processes by encouraging greater involvement of young people in sectorial policymaking which directly affects the youth. Among other priorities, the strategy also seeks to promote active citizenship in the form of volunteerism as a key route to interethnic interaction, reconciliation, and social integration (Ministry of Culture, Youth and Sport, 2013).

Thus, European integration remains a key driver of state-building efforts in Kosovo, and policy documents frame young Kosovars as essential to the construction of the new European state. Young people are presented as the central sites of intervention toward which social resources should be directed to build their capacity to be active citizens and key actors in addressing the social divides characterizing Kosovar society. However, while the existence of these laws and initiatives are important, their implementation has been uneven. Feltes (2013), who offers the most thorough study on the issue, demonstrates that post-war policy frameworks dedicated to enhancing youth participation have achieved a certain degree of success: $83 \%$ of the young people he surveyed felt that they had better opportunities for social and political engagement than before the war. However, he concludes that youth organizations remain largely influenced 
by political parties and the international community. As a result, an independent youth sector that pays clear attention to the concrete concerns of young people themselves is yet to exist.

\section{Our Study}

Despite often overwhelming societal challenges, many young Kosovars are actively involved in addressing social concerns. These young people engage in civic and social life and want to contribute to healing their society after the violent events they and their families have experienced. This study seeks to understand how highly-engaged Kosovar youth learn about issues of social concern and take an active role in addressing these concerns. A focus on young people's perspectives provides an important vantage point to assess further the implementation of post-war reconstruction policies that have placed priority on youth active citizenship in Kosovo.

Our exploration of the motivations and activities of highly-engaged Kosovar youth was part of the larger research project entitled "Pedagogies of Repair and Reconciliation: The Embodied Praxis of Youth Civic Engagement." This project, which we referred to as the Tikkun Youth Project, was a threeyear study that explored how highly-engaged youth across three countries (Canada, Kosovo, and South Africa) became aware of social injustices and sought opportunities for social change. The project wanted to highlight how the youth's knowledge of social injustices translated into embodied, lived experiencesof their activism. The project sought to use these insights to inform youth-led action projects that would help to identify and address ongoing social concerns.

The Tikkun Youth Project, as described in the introductory chapter, was organized around the concept of Tikkun Olam, an ancient Hebrew theological phrase meaning "healing the world." As Daniel and Antoniw (2016) explain, in its current practical and philosophical meaning, Tikkun Olam underscores the centrality of the actions of humans in the repair, healing, and reconciliation of social injustices. The phrase was used as a way of suggesting that humanity has a shared ethical responsibility to heal and transform the world. Despite the variances among participants and research sites, the notion of Tikkun Olam served as the inspiration for the 
researchers, youth activists, and community organizations to explore how young people were working for social justice, human dignity, and reconciliation in their specific communities.

As an analytical framework for making sense of young activists in Kosovo, we applied the "everyday network of youth politics" approach developed by Baczewska, Cachon, Daniel, and Selimos (2018) as part of the Tikkun Youth Project. This analytical framework is based on several propositions. First, it suggests that in understanding the engagement strategies of contemporary social change-oriented youth, "the distinction between formal and informal political engagement is becoming increasingly more difficult to sustain" (Baczewska et al., 2018, p. 291). While traditional arenas of socialization, such as the school and political parties, remain important to shaping young people's activities, young people are also engaging in what Giddens (1991) calls life politics-non-formalized ways of doing politics that involve lifestyle choices coalescing around broad-based social justice initiatives. Moreover, the analytical framework emphasizes the paradox that young people, due to the restriction placed on their lives, are also bound to a specific territorial location yet increasingly de-territorialized due to their access to information technologies and social media. Thus, their political activism is both local-shaped by the opportunities and restriction afforded in their local environments-as well as networked globally. Finally, the analytical framework suggests examining the strategic nature of young people's political and social engagements-their willingness to work through both formal and informal avenues to achieve their social change agendas. ${ }^{1}$

Methodologically, the larger project adopted a participatory approach to youth research in which young people actively participated as youth researchers under the guidance of university-based research experts. In participatory approaches, researchers collaboratively design projects that involve young people as co-researchers in various aspects of the research process, including project design, instrument design, data collection, and data analysis (Heath \& Walker, 2012). A participatory approach to youth research was adopted for several reasons. First, participatory research is reflexive about power relations between adults and youth, pays attention to how research contributes to the construction of dominant representations of young people, and explores how these representations inform the types of youth-oriented policies possible (Lesko, 1996). Second, although some raise concerns that incorporating youth co-researchers into the research process compromises the trustworthiness and validity of data (Sharpe, 2012), others 
have demonstrated that with adequate training and preparation, youth coresearchers can access experiences and perspectives unavailable to adults, thereby improving the overall quality of data collected (Schubotz, 2012; Sharpe, 2012). Finally, incorporating youth as co-researchers provides a space where young people can build confidence and develop important skills (Schubotz, 2012).

Within this larger conceptual and methodological framework, each research site was encouraged to adapt their approach to fit the specific context of their work. This flexibility allowed each research team to negotiate practically about the contextual features of their research site, but remain committed to the conceptual, methodological, and ethical components of the larger study. The notion of "flexibility within structure" aligns with Sharpe's (2012) insistence on the need to adopt flexible approaches to participatory research which holds that the level of youth participation may vary from step-to-step. It may not be necessary, possible, or desirable for young people to be involved in choosing the research topic and/or designing its overall objectives and the researcher may also wish to retain more control over data analysis procedures. This flexible approach is common in participatory research practices (McIntyre, 2008).

In Kosovo, we adopted a peer-to-peer interviewing approach in which five youth researchers were identified and trained to conduct semi-structured qualitative interviews with their highly-engaged peers. Youth researchers were active in various projects, clubs, and youth centers in their cities and were chosen for this project because of their previous experience with social activism activities. The youth researchers were themselves highly-engaged youth activists, although they varied in many aspects of their lives and engagement activities. Three females and two males between the ages of 18 and 21 years old participated in the project as youth researchers. One male was from the capital city Pristina, and the other male is from Prizren, the second largest city in Kosovo. Two females were from the divided northern city of Mitrovica, and the third female was from Rahovec, a mid-sized city located in southwest Kosovo. Youth researchers were involved in a variety of activities, such as advocating for gender equality, RAE rights, the social inclusion of children with Down Syndrome and other disabilities, interethnic reconciliation, and youth participation. In many ways, the youth researchers represented the social, cultural, and regional diversity of young people in Kosovo more generally.

To prepare for interviews, youth researchers participated in approximately 
twelve hours of training meant to orient them to the larger project. Training sessions involved explaining the goals of the project, acquainting youth researchers with effective interview techniques, and familiarizing them with the standards of ethical social research. An important component of the training sessions was dedicated to collaboratively reviewing and revising the initial interview guide. An initial draft interview guide was presented to the youth researchers who were asked to suggest revisions. The resulting interview guide was divided into two main parts. The first part included questions that aimed to map the personal background of the interviewee, including questions about their family, school experiences, friendships, leisure activities, and community life. The goal of these initial questions was to get a sense of how interview participants understood themselves, their social world, and ordinary ways in which they engage in day-to-day life. In the second part of the interview, specific questions were asked about their perspectives and practices of social activism. After completing the training and developing the interview guide, each youth researcher was then responsible for conducting two initial tape-recorded interviews with peers involved in various social activism activities. Interview participants were recruited by youth researchers through their networks. Each participant was informed of the scope of the research and their rights as voluntary research participants. Participants were then asked to sign a consent form.

After youth researchers completed these two initial interviews, the research team gathered to reflect on their experiences. Our conversation was divided into three main components. First, youth researchers were asked to reflect generally on their experiences of the initial interviews. Second, our conversation focused on specific analytical questions. Youth researchers were asked to discuss the following topics: the demographic characteristics of their interview participants (i.e., age, ethnicity, city/region where they lived); the range of activities interview participants were involved in; the participants' motivations to be engaged and impacts of their engagement; the ongoing community needs as identified by the participants; and the potential inconsistencies or limitations in the received information. The research team took detailed discussion notes on the conversation and developed preliminary themes addressing the main research questions of the project. Third, we used the insights generated during the discussion session to revise or refine the interview guide. Following this initial meeting and the second revision to the interview guides, youth researchers were then responsible for completing three more interviews. 
All interviews were then transcribed verbatim in the language (Albanian, Serbian, or English) in which the interview was originally conducted and then translated into English if needed. In total, twenty-four in-depth interviews were conducted by the youth researchers. Interview participants ranged in age from 17 to 24 years old. Thirteen males and eleven females were interviewed, and they came from various regions throughout the country, with $71 \%$ residing in urban areas. All participants were chosen by the youth researchers based on the participants' social activism activities and their desire to make a difference in their communities. Participants were Albanian $(n=16)$, Roma, Ashkali and Egyptian $(n=4)$, Serbian $(n=3)$, and Bosniak $(n=1)$. Interviews lasted around one hour.

The adult researchers and facilitators for the Kosovo site (Ereblir Kadriu, Erwin Dimitri Selimos, and Janet Balyeat) analyzed the English versions of the interview transcripts and developed themes to describe interview participants' social engagement activities and experiences. Through our analysis, we developed a list of preliminary findings which were written as detailed analytical memoranda. We then met with the youth researchers and presented to them the analytical memoranda and initial findings. Adapting Frisina's (2010) "back-talk focus group" format, we asked the youth researchers to agree, disagree, and/or qualify our conclusions and insights. In their responses, we probed specifically for how their own experiences as highly-engaged activists related to the insights documented in the analytical memoranda. The inclusion of the youth researchers' own engagement experiences through their "back-talk" added a level of youth participation in the analysis process and additional empirical detail and richness to complement interview insights.

\section{Findings}

How do highly-engaged Kosovar youth learn about issues of social concern and take an active role in addressing these concerns? What motivates their involvement and what impact does it have on them as individuals as well as the larger society? In what follows, we organize our findings into the following sections: Motivations to Get Involved; Ways of Learning About 
Initiatives; Places of Engagement; and Benefits, Risks, and Impact of Engagement.

\section{Motivations to Get Involved}

Highly-engaged youth demonstrated an interest in a range of issues and activities, including the promotion of gender equality, human and minority rights promotion, sexual health promotion, the inclusion of people with disabilities, interethnic reconciliation and peace-building, social integration of the RAE communities, anti-discrimination programs, and educational improvement.

Participants cited deep personal tragedies and experiences as primary motivations that compelled them to join existing organizations, campaigns, or initiatives that addressed issues of social justice. For example, Donika, a young activist, connected her participation in interethnic reconciliation and peace-building to a confluence of personal experiences, including witnessing the destruction of war, losing friends because of the politicization of ethnicity during the war, and her experiences as a refugee in Europe, where she felt firsthand the effects of social and racial stigmatization. When she returned to Kosovo, Donika dedicated herself to reconciliation efforts between Serbs and Albanians because, as she tells us, "I did not want other kids from Kosovo to experience what I experienced."

Participants also remarked that their deep personal attachments to local communities motivated them to look for opportunities to improve the conditions of local life. For instance, when asked what motivated him to become a social activist, Jon, an 18-year-old from the ethnically-divided northern city Mitrovica, responded that he wanted "to see the city better, to see the city [that has] suffered in the war, has suffered in the past ... [In] history Mitrovica was a 'big place' ... but it became a dark place. So, I really want to see this place a bit brighter ... Maybe I might have something this city needs."

Participants also expressed several pragmatic considerations when asked what motivated their social engagement activities. These interests were not related to concerns about social injustices, but rather emerged from a desire for self-development. For example, some participants chose to volunteer because they wanted to gain work experience, enhance their resumes, and 
develop new competencies and skills that would improve their prospects in a highly competitive society that lacks opportunities for young people. For others, being involved in social engagement activities was a way to have fun: they could spend time with friends, make new friends, and learn new things. A very important factor in motivating participation cited by many young people was that available trainings and programs often offered young people the ability to travel throughout Europe-an important motivating factor given that Kosovars continue to experience significant travel and visa restrictions.

\section{Ways of Learning About Initiatives}

These young people learned about potential opportunities from friends, during informal and formal school presentations made by Civil Society Organizations, official public campaigns, or through acquaintances they knew from previous events or initiatives in which they participated. For example, Pajtim became involved in the Young Men's Initiative after being introduced to the project during a presentation at school. ${ }^{2}$ He "liked their ideas" and joined several workshops as a participant. Inspired by the things that he learned, he now works three hours a week with the organization as a project coordinator where he assists with various outreach initiatives and workshops, including anti-homophobia campaigns, educating young people about family-based violence, and the ways in which young men could express "their feelings in an easier way." During his interview, he reflected on how he sees his work on gender equality as part of a larger process of social change in Kosovo:

Our society has learned to do what our elders did. They basically told us what to do and we followed their orders ... We are trying to figure out our way. We are following some rules ... we don't even know who invented them, or that are written somewhere. When we stop and think, we are offending someone or they bring no good.

Many participants echoed Pajtim by stating that involvement in one initiative encouraged or snowballed into more initiatives. Through exposure to one issue, some became aware of and interested in additional social issues. Their 
involvement connected them to people, either peers or older persons, and organizations through which they received information about additional opportunities. The ongoing participation in different national and international social activities and projects led to the development of an identity as a civically engaged and socially responsible young person in Kosovo.

Family practices and parental support, especially around attitudes toward gender, were very important in shaping young people's motivations and social activism. Most participants spoke about how their parents were supportive of their social activities and argued that this was not the case for many other young people in Kosovo. One of our youth researchers, herself highly active in interethnic reconciliation and a director of a NonGovernmental Organization (NGO) that has been working to promote youth civic engagement and volunteerism, suggested that her outreach experiences revealed that many parents in rural areas, who often adhere to more traditional attitudes toward male and female roles, are reluctant to allow their daughters to "create friendships or go in some activities." This contrasts with another interview participant, a member of the Bosnian community living in Northern Mitrovica, whose parents were very supportive of her involvement in interethnic reconciliation efforts and escorted her weekly from Northern Mitrovica to attend conferences and workshops outside the city.

High schools were identified as a major pathway to learning about highly engaging projects, activities, or initiatives. Participants cited presentations and trainings done in their schools conducted by organizations such as the Red Cross (which included First Aid training, and information trainings about STDs and AIDS), Be a Man Clubs (an initiative originally funded by the CARE International Network), and Peer Education Network, which also trains youth about sexual reproductive health as well as safe and healthy sexual behaviors. In this way, schools enabled social and civic youth activism by being the distributer of the information, as well as the place for young people to meet and attend different workshops and trainings organized by non-governmental and youth organizations. 


\section{Places of Engagement}

Conversations with highly-engaged youth revealed that a clear majority of young people's social change efforts took place in non-governmental organizations and/or youth organizations. Some participants were in fact leading representatives of these civil society organizations. A nexus of international and local organizations provided spaces and activities that young people could become engaged in. The issues or concern of focus were, therefore, not necessarily what the youth felt were most important issues in their communities. Instead, funding, often from international organizations and governments, drove these types of actions. However, in some cases young people used these organizations to design and create their own initiatives, actions, and activities.

What seemed to emerge in our conversations with highly-engaged youth was the perception that they were part of a loose network of active young people, evidenced by concerns expressed by some that "in every training [the] same people participate, not different people. New people don't join us." Conversations also revealed that many highly-engaged youth developed an identity as "active youth" in contradistinction to the passive or apathetic youth of Kosovo, which were characterized by our participants as constituting most young people in Kosovo. Most of our participants differentiated themselves from their fellow peers. They tended to see themselves as active, while depicting most young people as disengaged or even apathetic. They provided different reasons for the assumed passivity of other young people: some blamed young people who they thought did not care, had no hope, or were more concerned with having fun or being popular, and others suggested that adults and the government ignored young people's ideas or did not do enough to reach out and learn from them.

\section{Benefits, Risks, and Impacts of Engagement}

Participants identified many positive benefits of their social activism. Their involvement was important in their own self-development and enhanced their perspectives. Involvement gave them an opportunity to learn new things and travel to places outside of Kosovo to attend study visits and 
conferences. Other participants reported on the positive benefit of building their resumes and advancing their credentials. On a more affective level, social activism made many young people feel better about themselves. Their involvement improved their self-esteem and self-respect. Working jointly on projects made some of them feel more connected to their friends and colleagues. This sense of accomplishment and human connectedness is summarized by one of our youth researchers who told us that just seeing the "smiles from children of different people from different ethnic backgrounds" during workshops on interethnic reconciliation justified her efforts. Such an image provided a sense of hope within a societal context characterized by many difficult social and political challenges.

Young activists pointed to positive community changes engendered by their activities. In Mitrovica, for example, a group of young people did a study of what their community needed, and one identified a need for public toilets in the city. They petitioned the municipality and as a result, there are now two public toilets in the city which are maintained by municipal finances. In Prishtina, several young men from the Be a Man Club organized a public cooking activity in the city center in which boys cooked food publicly in the city square and gave it away for free to any passerby. The initiative was designed to encourage discussion about changing gender roles in society and, specifically, to create dialogue about conceptions of masculinity. According to one youth activist involved in the cook-in, many men approached them and questioned why they were performing women's work. This opened an opportunity for a discussion about gender equality. One participant who is highly active in promoting the rights of RAE communities spoke of establishing a radio station specifically for the RAE communities living in the municipality of Gjakova. This initiative was meant to address the fact that many RAE members cannot read and/or are hesitant to approach government officials due to a long history of discrimination and abuse. As such, the radio station was designed specifically to educate the RAE community of their legal rights and to act as an essential source of information about various programs, activities, and services. $\underline{3}$

Although attempting to address social issues had important positive impacts on both young people personally and on their communities, being active, especially around controversial topics and issues, was risky and led to criticism from other people. Some young people spoke about being teased or criticized for their activities in ways that were meant to disparage their efforts, beliefs, and goals. For example, one young female Albanian activist, 
who at the time of our conversation had been active in interethnic reconciliation in Mitrovica, spoke about being criticized by her Albanian peers for speaking Serbian (she is fluent in Serbian) with Serbian peers. One time, she was accused of being Serbian, which was intended as a threatening and disparaging comment:

I speak Serbian fluently and in trainings when I talk to Serbs, my friends usually say to me, "Why do you speak Serbian? Where did you learned it?" [Interviewer: Do they say it in a mean way?] Sometimes, yes. I know also of some of my friends being asked, "Why do you cooperate with Roma people or other ethnicities?"

A common point of discussion in our conversations was the sense among many young activists of the overwhelming number of social needs that have to be addressed in Kosovo. Several spoke of the need to get other people involved in various initiatives and to increase the number of young people instead of only including those who have already been participating. Others spoke of the need for educational campaigns to increase people's knowledge of human rights, to educate people about domestic violence, and to inform people about the struggles of people living with disabilities in Kosovo.

In sum, traditional institutions of socialization, such as families and schools, remain important in enabling young people's social engagement. A strong sense of attachment and identification with local places, like their neighborhood, city, or town, emerged as an important factor underpinning their desire to address social issues. Participants also expressed a mix of social-ethical and instrumental reasons for their engagement. Social engagement was viewed as important to "building a better society," but also as a means of gaining skills and experiences advantageous in a society attempting to reconstruct and integrate itself into international financial, political, and cultural institutions, namely the European Union. Their social change efforts most often took place in non-governmental organizations and youth organizations, frequently funded by international organizations. These organizations enabled their engagement by introducing youth to new issues and providing them with initiatives to get involved in addressing them. Through doing so, these organizations also shaped the topics and nature of the youth social engagement agenda. Finally, their social change activities had important benefits on their sense of self and often resulted in practical changes to their local communities. 


\section{Concluding Remarks}

Our exploratory research points to interesting questions that we believe deserve further exploration and analysis. First, non-governmental and youth organizations are critical in shaping young people's engagement activities, including the very types of issues they attempt to address because funding arrangements and organizational missions often drive programing. While highly-engaged youth are often committed to addressing the issues and concerns identified by these organizations and advocate through and within these organizations, there is still a need to explore the extent to which young people themselves participate in setting the agenda and how this participation might vary based on organizational setting. Furthermore, few interview participants spoke about participating in policy-decisions through government-sponsored youth centers. This could be an issue of sampling, but the relative absence of this experience may also point to the ineffective implementation of youth participation rights as articulated in official Kosovar laws (see Feltes, 2013).

Second, highly-engaged youth suggest that families have a significant impact on accessing programs and initiatives. This is not surprising given the enduring influence of familialism in Kosovo. However, there are many questions that warrant more research, and these include exploration of factors which explain families' reluctance to allow their children to participate in these initiatives. As noted earlier, an important social distinction in Kosovo is between the rural and urban folk. These distinctions are often framed through explicit value distinctions-rural lifestyles tend to be more conservative, traditional, and religious, while urban lifestyles were more progressive "European" and cosmopolitan. Many of these programs and initiatives articulate liberal social change agendas and are targeted to specific cultural issues, like gender equality or interethnic prejudice reduction. To what extent are the identified issues of participation the result of a collision of differing value orientations?

Third, and related to the point above, our conversations reveal what appears to be networks of inclusion and exclusion with respect to young people's participation in social initiatives. Participants spoke about their impressions that "in every training [the] same people participate, not different people. New people don't join us." Such comments suggest that participation is being confined to a loosely-structured network of young 
people. Given the EU integration thrust and value-sets of these programs, this raises the question of the extent to which this uneven participation reproduces social distinctions among youth. Even more, does this uneven participation reproduce inequalities through an unequal distribution of social and cultural capital? Are certain youth being "left behind" as Kosovar society attempts to reconstruct and integrate itself into international financial, political, and cultural institutions, namely the European Union?

Future research should examine young people's participatory experiences in non-governmental youth-focused organizations, consider the degree of participatory influence they have in shaping the agenda and activities of these organizations, and document the processes of implementing youth participation in policy decisions as outlined by Kosovar laws. This research should also consider the unequal impact that participation may have on youth and consider practical strategies to enhance youth participation in the third sector. Such research would provide valuable information that could be used to enhance the effectiveness of the youth sector in Kosovo.

\section{References}

Baczewska, E., Cachon, M. F., Daniel, Y., \& Selimos, E. D. (2018). Mapping the terrain of strategic politics among social change-oriented youth. Journal of Youth Studies, 21(3), 288-303. doi:10.1080/13676261.2017.1366649

Berisha, I., \& Kunushevci, L. (2017). The legacy of colonialism in Kosova: An interview with Ibrahim Berisha. Global Dialogue: Magazine of the International Sociological Association, 7(3). Retrieved from http://globaldialogue.isa-sociology.org/the-legacy-of-colonialismin-Kosovo-an-interview-with-ibrahim-berisha/

Cani, B. (2015, February 13). Lack of opportunity lead to mass exodus from Kosovo. Deutsche Welle. Retrieved from http://www.dw.com/en/lack-ofopportunity-leads-to-mass-exodus-from-kosovo/a-18256218

Clark, H. (2000). Civil resistance in Kosovo. London, U.K.: Pluto Press.

Daniel, Y., \& Antoniw, J. (2016). Introduction to youth-led civic engagement for Tikkun: A developing partnership across borders (Canada, South Africa and Kosovo). Citizenship Education Research Journal, 5(1), 3-13. Retrieved from http://ejournals.ok.ubc.ca/index.php/CERJ/article/view/13 
EULEX. (n.d.). What is EULEX? Retrieved from https://www.eulexkosovo.eu/?page $=2,16$

Feltes, T. (2013). Youth and democracy: The promotion of youth participation by the international community in Kosovo. Security \& Human Rights, 24, 195-209. doi:10.1163/18750230-02402010

Frisina, A. (2010). Young Muslims' everyday tactics and strategies: Resisting Islamophobia, negotiating Italianness, becoming citizens. Journal of Intercultural Relations, 31(5), 557-572. doi:10.1080/07256868.2010.513087

Giddens, A. (1991). Modernity and self-identity: Self and society in the late modern age. Cambridge: Polity.

Gjinovci, R. (2016). Kosovo's education system amongst the worst in the world. Prishtina Insight. Retrieved from https://prishtinainsight.com/ kosovos-education-system-amongst-worst-world/

Gjocaj, S. (2016). Kosovo's poor future. Prishtina Insight. Retrieved from https://prishtinainsight.com/kosovos-poor-future/

Gola, A., \& Selaci, G. (2017). Socio-political and religious dynamics in Kosovo from the post-secularist perspective. Croatian Political Science Review, 54(4), 85-108. Retrieved from https://hrcak.srce.hr/190339

Heath, S., \& Walker, C. (2012). Innovations in youth research. Houndsmills, UK: Palgrave MacMillian.

Kosovo Agency of Statistics. (2017). Statistical yearbook of the Republic of Kosovo. Prishtina, Kosovo: Kosovo Agency of Statistics, Republic of Kosovo. Retrieved from http://ask.rks-gov.net/en/kosovo-agency-of-statistics/ add-news/statistical-yearbook-of-the-republic-of-kosovo-for-2017

Krasniqi, G. (2013). State borders, symbolic boundaries and contested geographical space. Transitions, 52(2), 29-51. Retrieved from https://www.research.ed.ac.uk/portal/files/15270778/

State borders symbolic boundaries and contested geographical spa ce.pdf

Lesko, N. (1996). Past, present, and future conceptions of adolescence. Educational Theory, 45(4), 453-472. doi:10.1111/j.1741-5446.1996.00453.x

Malcolm, N. (1998). Kosovo: A short history. New York City, NY: New York University Press.

McIntyre, A. (2008). Participatory action research. Thousand Oaks, California: SAGE Publication, Inc.

Ministry of Culture, Youth and Sport. (2013). Kosovo Strategy for Youth, 2013-2027. Retrieved from https://www.mkrs-ks.org/repository/docs/ KOSOVO STRATEGY FOR YOUTH.pdf 
Pasha, A., Xhangolli, K., Dundo, J., Gjokuta, B., Tahiri, Z., \& Lena, O. (2012).

Kosovo youth study: Forward looking, grounded in tradition. Friedirch Ebert Stiftung and IDRA Research \& Consulting. Retrieved from http://www.idracompany.com/en/news-publications/publications/ kosovo-youth-study-2012

Republic of Kosovo. (2009). Law on the empowerment and participation of youth. Retrieved from http://www.youthpolicy.org/national/ Kosovo 2009 Youth Law.pdf

Schubotz, D. (2012). Involving young people as peer researchers on community relations in Northern Ireland. In S. Heath \& C. Walker (Eds.), Innovations in youth research (pp. 101-120). Houndsmills, UK: Palgrave MacMillian.

Sharpe, D. (2012). Young people and policy research: Methodological challenges of CYP-led research. In S. Heath \& C. Walker (Eds.), Innovations in youth research (pp. 161-177). Houndsmills, UK: Palgrave MacMillian.

Tahiri, P. (2014). Concepts of citizenship among school students in Kosovo. Kosovo Education Center. Retrieved from https://phzh.ch/globalassets/ ipe.phzh.ch/forschung-und-lehre/concept-of-citizenship-amongschool-students-in-kosovo.pdf

UNDP Kosovo. (2017). Public pulse XIII. Retrieved from http://www.ks.undp.org/content/kosovo/en/home/publications.html

1 Please see Baczewska et al. (2018) for a more detailed discussion of this analytical framework.

2 Led by CARE International, the Young Men's Initiative has been implemented throughout the Balkan region with the aim of building more gender-equitable and non-violent lifestyles among youth. The initiative uses media campaigns and school-based curriculum to encourage young men to reflect on how gender norms lead to the inequitable treatment of women and girls. For more information, please see http://www.icrw.org/wherewe-work/young-men-initiative-balkans

$\underline{3}$ See, for instance http://birn.eu.com/uncategorized/rae-communityestablishes-a-radio-station-in-gjakova/ and Radio Prosperiteti at http://www.radioprosperiteti.com/ 